\title{
Synthesis of Highly Porous Catalytic Layers for Polymer Electrolyte Fuel Cell Based on Carbon Aerogels
}

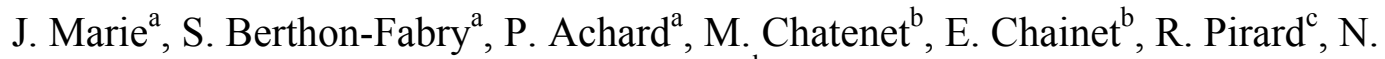 \\ Cornet $^{\mathrm{d}}$ \\ ${ }^{\mathrm{a}}$ Center for Energy and Processes (CEP), ENSMP, CNRS FRE 286, BP 207, 06904 \\ Sophia Antipolis Cedex, FRANCE \\ ${ }^{\mathrm{b}}$ Laboratoire d'Electrochimie et de Physicochimie des Matériaux et des Interfaces \\ (LEPMI), UMR 5631 CNRS-INPG-UJF, ENSEEG, BP 75, 38402 Saint-Martin d'Hères \\ Cedex, FRANCE \\ ${ }^{c}$ University of Liège, Laboratoire de Génie Chimique B-4000 Liège, BELGIUM \\ ${ }^{\mathrm{d}}$ RENAULT, TCR-DR/64240, 78288 Guyancourt, FRANCE
}

\begin{abstract}
Recent studies of the PEMFC catalytic layer electrocatalyst support showed that high surface area carbon blacks cannot be used efficiently (1) because they have necessarily small primary pores that yield high diffusion limitation for the oxygen reduction reaction (ORR). In the present paper, we first synthesized and characterized carbon aerogels which exhibit high surface area, high porous volume and adjustable pore-size distribution. In that way, they enable to decouple between surface area and porosity, while they are also promising electrocatalyst supports (2). Second, we elaborated new catalytic layers made from 2 different carbon aerogels with 2 different Nafion loadings. Finally, we characterized the structure of such catalytic layers, and evaluated their activity towards the oxygen reduction reaction (ORR). Finally, an appropriate catalyst support should display large pore-size and high surface area in order to reduce the PEMFC cathode platinum loadings without loosing activity, following the reduction of oxygen diffusion limitation.
\end{abstract}

\section{INTRODUCTION}

The catalytic layer of the PEMFC is a key element of the cell. Most of its volume fraction consists of the electronically conductive support of the electrocatalyst, which thus determines the structure of the catalytic layer. Up to now, the material used as electrocatalyst support was mainly carbon black, about which recent studies showed it cannot be efficiently used in catalytic layers (1). Indeed, such materials do not enable the decoupling between surface area and porosity. So, in order to go beyond this issue, we have investigated the use of carbon aerogels as electrocatalyst support (2). The major difference between carbon blacks that are commonly used as catalyst support and carbon aerogels is their structure. Carbon aerogels have monolithic structure whereas carbon blacks have aggregates structure. Whereas carbon aerogel in the catalytic layer consists of micron size grains that are electronically conductive due to their carbon skeleton, the carbon blacks aggregates, which are one order of magnitude smaller, are connected through Van der Walls bonds. They are thus subjected to electronic insulation by the proton conducting polymer Nafion, which needs to percolate into this layer. The 
monolithic structure of the carbon aerogel also implies that the pores of the carbon matrix do not depend on the random-like dispersion of small carbon blacks aggregates into the catalytic layer but is controlled by the synthesis parameters of the carbon aerogel. This study is focused on measuring the porous structure of carbon aerogel based catalytic layers and evaluating the influence of this structure on the electroactivity of the layers. They are measured in half cell cathode configuration, which enables simpler operating conditions than PEM fuel cell testing.

\section{Materials preparation.}

\section{EXPERIMENTAL}

The carbon aerogels were synthesized with a commonly used (3) sol-gel technique. Resorcinol ( $\mathrm{R})$ and formaldehyde $(\mathrm{F})(\mathrm{F} / \mathrm{R}=2$ molar ratio) were dissoluted into distilled and deionised water. The gelation catalyst $(\mathrm{C})$, sodium carbonate, was added and the gels underwent gelation in sealed glass tubes at $80{ }^{\circ} \mathrm{C}$ for 3 days. The two different reactants molar ratios $(\mathrm{R} / \mathrm{C})$ are presented in Table 1 as well as the mass fraction of reactants in the sol (\%solids). The so obtained gels were dried under supercritical conditions of $\mathrm{CO}_{2}$ after water exchange with acetone. The organic aerogels were pyrolysed at $1050{ }^{\circ} \mathrm{C}$ for 30 minutes under flowing nitrogen $\left(3 \mathrm{~L} \mathrm{~min}^{-1}\right)$.

The platinum insertion was made on the so obtained carbon aerogels. For that purpose finely grinded carbon aerogel powder samples were suspended in $\mathrm{H}_{2} \mathrm{PtCl}_{6}$ solution. Since the platinum salt is a strong acid, the $\mathrm{pH}$ of the impregnation solution was acidic $(\mathrm{pH}=$ 2.2). The impregnation lasted $48 \mathrm{~h}$ and the platinum salt reduction was achieved using $\mathrm{NaBH}_{4}$. The quantity of reductant added to the impregnation mixture was $8 \mathrm{x}$ the stoichiometric quantity of platinum to ensure the complete reduction of the platinum salt. The powder was then washed thoroughly with boiling water and filtered. The so obtained Pt-doped carbon aerogels contained both $15 \mathrm{wt} \%$ of platinum.

The synthesis of the catalytic layers for the porosimetry measurement was made by the decal process (4). The Pt-doped carbon aerogel powder was suspended into a water solution with $0.3 \mathrm{wt} \% \mathrm{Nafion}^{\circledR}$ made from a commercial $10 \mathrm{wt} \% \mathrm{Nafion}^{\circledR}$ in water (Ion Power Inc.). Two different mass ratios Nafion ${ }^{\circledR} /$ Carbon $(\mathrm{N} / \mathrm{C})$ were used: 0.41 and 0.82 . The samples were thus called CA\#1 or CA\#2 -N25 and $-\mathrm{N} 40$ in reference to the wt $\%$ of Nafion into the catalytic layers so obtained. The ink was magnetically stirred for 24 hours and then sonicated for 10 minutes before spraying onto Kapton ${ }^{\circledR}$ decals. The decals were hot pressed $\left(120^{\circ} \mathrm{C}, 200 \mathrm{~kg} \mathrm{~cm}^{-2}\right)$ onto one side of NE1035 Nafion membranes. This half MEA constituted the samples for porosimetry measurements. The comparative electrochemical performances of the layers could not be measured on those samples because of the geometry of the PTFE electrochemical cell, which required using a hard support such as a GDL to enable electronic contact. Thus, the same layers were sprayed onto GDL (Freudenberg GmbH) for the electrochemical measurements.

\section{$\underline{\text { Samples Characterization }}$}

Porosity Measurements. The carbon aerogels and catalytic layers porosity were both measured from nitrogen sorption isotherms at $77 \mathrm{~K}$ on a Carlo Erba Sorptomatic 1900 device and mercury porosimetry on a Carlo Erba Porosimeter 2000 (2000 bars maximum pressure). The $\mathrm{Hg}$-porosimeter was used at its lowest pressure sweep rate so that the porous volume data was recorded at the equilibrium. The catalyst-coated membrane was cut into $1 \mathrm{~cm}$ wide bands that could fit inside the porosimeter sample holder. The BET 
technique was used to calculate the specific surface area $\left(\mathrm{S}_{\mathrm{BET}}\right)$ of the materials. The microporous volume $\mathrm{V}_{\mathrm{MIC}}$ was estimated from the Dubinin-Radushkevitch technique. The porous volume $\mathrm{V}_{\mathrm{P}}$ of the samples consists of the sum of three porous volume: the microporous volume, the mercury porous volume and the mesoporous volume $\mathrm{V}_{\mathrm{MES}}$ between 2 and $7.5 \mathrm{~nm}$. This latter volume was calculated from nitrogen sorption isotherm with the Broekhoff and de Boer method between 2 (micropore limit) and $7.5 \mathrm{~nm}$ pore size which is the limit available by mercury porosimetry at 2000 bar. The pore size distribution is determined by the Washburn equation [1] in the high pressure domain where the intrusion occurs.

$$
L=\frac{4 \gamma \cos \theta}{P}
$$

where $\mathrm{L}$ is the diameter considered as cylindrical, $\gamma=0.48 \mathrm{~N} / \mathrm{m}$ is the mercury surface tension, $\theta$ is the contact angle between mercury and the material (usually $\theta=140^{\circ}$ ) and $\mathrm{P}$ is the pressure. In the pressure domain where the material shrinks under the isostatic pressure, the pore size distribution is determined by the buckling equation [2] proposed by Pirard et al. (5)

$$
L=\frac{k_{f}}{P^{0.25}}
$$

where $k_{f}$ is the buckling constant determined by the equality of equation 1 and 2 at the pressure of the mechanism change.

The carbon aerogels CA\#1 and CA\#2 basic porosity data are shown in Table I. The bulk densities were measured with a pycnometer. The porous volume $V_{p}$ approaches the void volume $V_{\mathrm{v}}$ that can be calculated from the simple formula (with $\rho_{\mathrm{s}}$, the carbon skeleton density $\sim 2$ ):

$$
V_{V}=1 / \rho_{b}-1 / \rho_{s}
$$

Table 1 exhibits that our two carbon aerogels have similar properties in terms of surface area and porous volume. They can mainly be differenced by their pore size distribution as it will be shown latter.

TABLE I. Porosimetry basic data of carbon aerogels

\begin{tabular}{ccccccccc}
\hline Sample & R/C & \%solid & $\begin{array}{c}\rho_{\mathrm{b}} \\
\left(\mathrm{g} . \mathrm{cm}^{-3}\right)\end{array}$ & $\begin{array}{c}\mathrm{S}_{\mathrm{BET}} \\
\left(\mathrm{m}^{2} \mathrm{~g}^{-1}\right)\end{array}$ & $\begin{array}{c}\mathrm{V}_{\text {mes }}(2-7.5) \\
\left(\mathrm{cm}^{3} \mathrm{~g}^{-1}\right)\end{array}$ & $\begin{array}{c}\mathrm{V}_{\text {mic }}(<2) \\
\left(\mathrm{cm}^{3} \mathrm{~g}^{-1}\right)\end{array}$ & $\begin{array}{c}\mathrm{V}_{\mathrm{Hg}}(>7.5) \\
\left(\mathrm{cm}^{3} \mathrm{~g}^{-1}\right)\end{array}$ & $\begin{array}{c}\mathrm{V}_{\mathrm{p}} \\
\left(\mathrm{cm}^{3} \mathrm{~g}^{-1}\right)\end{array}$ \\
\hline CA\#1 & 300 & 5 & 0.15 & 669 & 0.12 & 0.33 & 5.15 & 5.6 \\
CA\#2 & 200 & 10 & 0.19 & 565 & 0.09 & 0.26 & 4.45 & 4.8
\end{tabular}

Catalytic activity measurement: The catalytic layers $(0.5 \mathrm{~cm}$ diameter $)$ deposited on the GDL were placed inside in a PTFE holding cell already described (6). The GDL side was placed on a porous conductive backing which provided for a gas inlet through the GDL. The catalytic layer side was immersed in the $1 \mathrm{M}$ sulfuric acid solution contained in a three-electrode cell. The working electrode was connected to a potentiostat PAR 273 $($ EG\&G) with a standard calomel reference electrode $(+0.245 \mathrm{~V} / \mathrm{NHE})$ and a platinum 
plate counter electrode. The active area of platinum for the catalytic layer was determined measuring the $\mathrm{H}$-adsorption/desorption coulometry, according to the following experimental procedure. At ambient temperature, nitrogen gas was firstly bubbled in the solution and through the GDL at the same time. Before the potential cycling started (100 $\mathrm{mV} \mathrm{s}^{-1}$ between -0.25 and $+1.2 \mathrm{~V} / \mathrm{SCE}$ ), the nitrogen gas inlet flux that cross the GDL was reduced until no bubbling was observed through the catalytic layer. The bubbling into the solution was also stopped and a nitrogen stream was maintained over the liquid surface. Such experimental procedure implied a small overpressure on the back side of the porous layer. Thus we can expect that the catalytic layer is not fully flooded by the acid solution whereas the highly hydrophilic Nafion ${ }^{\circledR}$ should be fully wetted. The quasisteady state measurement of the oxygen reduction reaction activity $\left(1 \mathrm{mV} \mathrm{s}^{-1}\right.$ between +0.7 and $-0.1 \mathrm{~V} / \mathrm{SCE}$ ) was done following the same procedure changing nitrogen into oxygen, as previously explained in (6).

\section{RESULTS AND DISCUSSION}

\section{$\underline{\text { Catalytic layer porosity measurement }}$}

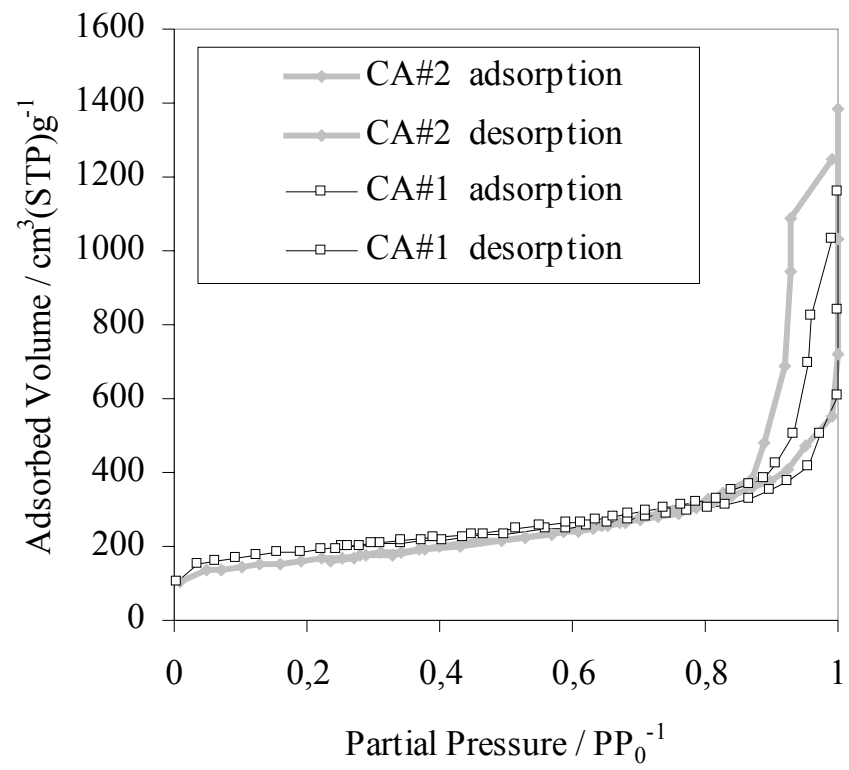

Figure 1. $\mathrm{N}_{2}$-sorption $77 \mathrm{~K}$ isotherms for carbon aerogels $\mathrm{CA \# 1}$ and $\mathrm{CA \# 2.}$

Firstly, the sorption isotherms of CA\#1 and CA\#2 (Fig. 1) give a general idea of the pore size distribution range for each carbon aerogel. The isotherms are type II following the BDDT classification of Broekhoff and de Boer (7). The hysteresis loop between sorption and desorption curve illustrates that CA\#1 and CA\#2 both have mesopores. They also have micropores, as evidenced by the volume $\mathrm{V}_{\text {mic }}$ determined by the DubininRadushkevitch method and macropores (over $50 \mathrm{~nm}$ ) because of the un-defined volume at saturation.

Figure 2 shows the Hg-porosimetry compression curve for CA\#1 and CA\#2 as well as for the layers. The same way the $\mathrm{N}_{2}$-sorption BET surface area do not rely on any model of pores, the porous volume so-obtained do not depend on any relation between 
Hg-pressure and pore size. In order to understand the mechanism of volume change induced by the compression, a low pressure run (500 bars maximum pressure instead of 2000 bars) is applied to CA\#1 (Fig. 2(a)). The weight of the samples is also measured before and after the measurement. In the case of the low pressure run on CA\#1, no weight increase was measured whereas after the 2000 bars maximum pressure run, the weight of the sample increased a lot. The weight increase signifies that mercury has intruded into the carbon aerogel structure and some remained trapped into its porous structure even after decompression (it is also confirmed from optical microscope observation). The $\mathrm{Hg}$ intrusion into the porous structure is evidenced by the sharp porous volume increase beyond 1000 bars. Now, looking at the curves of figure 2 with more precision, we should point out that the low density carbon aerogels are firstly compressed and only at high mercury pressure is the recorded volume variation due to mercury intrusion into the sample. This means that Washburn equation [1] can only be used in the high pressure region to calculate the pore size distribution. In the lower pressure domain, the pore size distribution is calculated by the hierarchical pore collapse theory (5). The Nafion compression data (multiplied by 10 because the layer mass is about one tenth of the Nafion membrane mass) is also shown on Fig. 2(a). All the layers show evident irreversibility (similar to carbon aerogels data) with a similar sharp increase at a pressure over 1000 bars. Thus we can conclude that the layers are also intruded by the mercury (which is by the way confirmed from the important mass increase after porosimetry run) at high pressure, like for the carbon aerogels they are made from. This further means that the same model can be used to calculate the pore size distributions of the carbon aerogels and the layers.

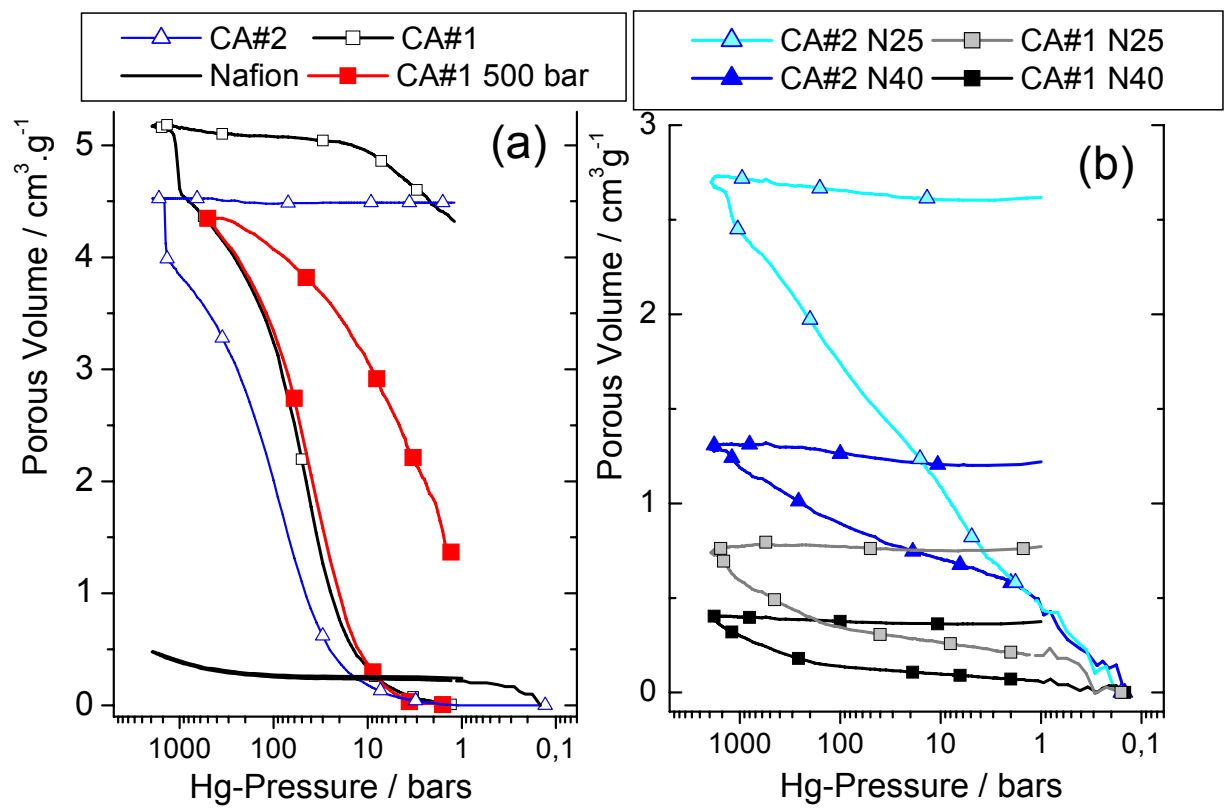

Figure 2. (a) Mercury porosimetry measurements until 2000 bars on carbon aerogels CA\#1 and CA\#2 and Nafion membrane (x10) with two different pressure (2000 and 500 bars) range for CA\#1 (b) Mercury porosimetry measurement on the catalytic layers.

The so calculated pore sizes distributions are shown on Fig. 3. The CA\#1 and CA\#2 distributions are divided by 2 so that the layers pore size distributions can be seen well. It 
is worth noticing that the pore size distributions of the layers do not show primary and secondary pores commonly observed in the case of carbon black-based catalytic layers (8). This means that the carbon aerogels inter-grains porosity is intruded by the Nafion (during ink spray and hot pressing) and no other pores than the carbon aerogel pores (modified by the Nafion) exist in these layers.

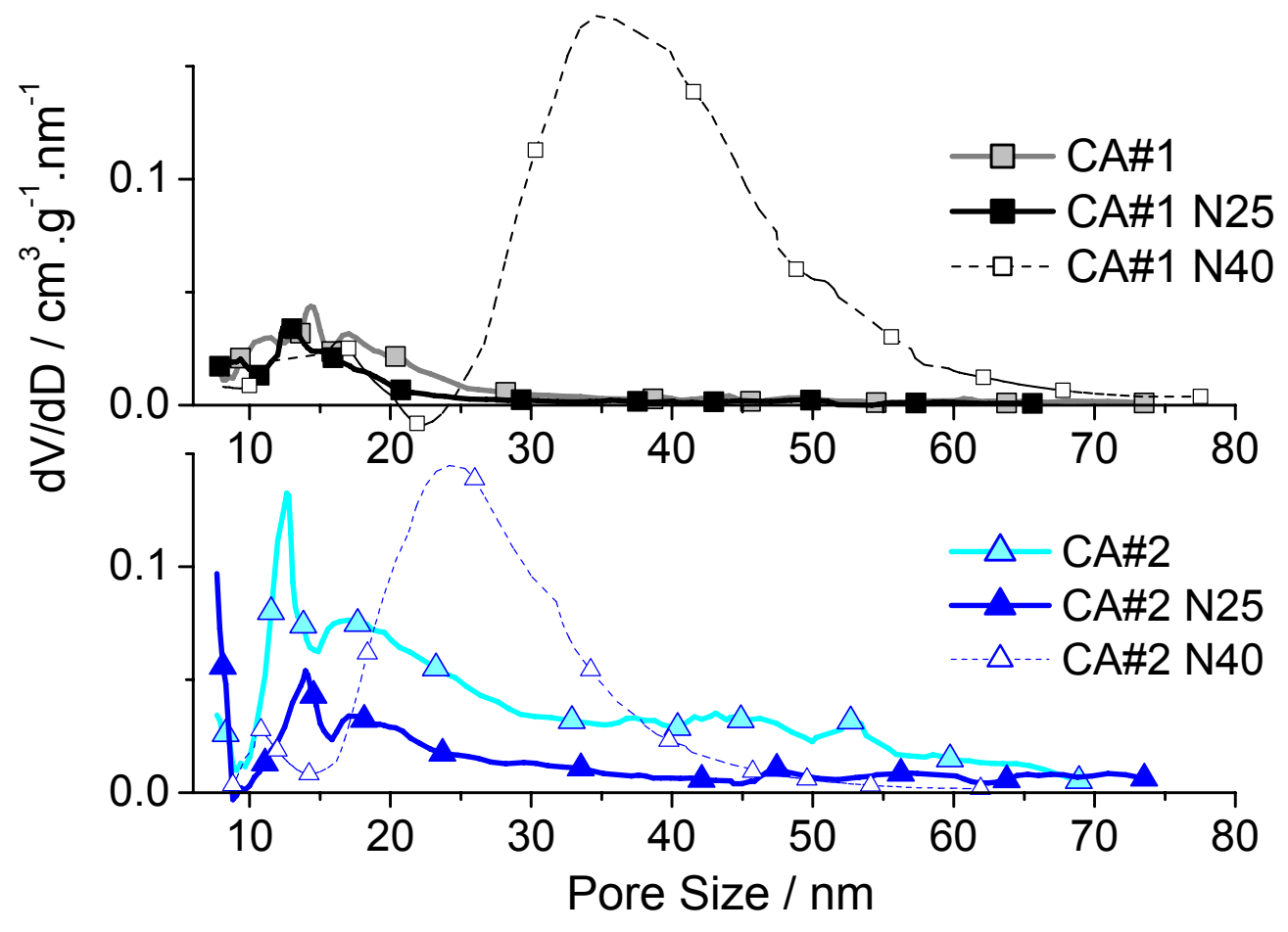

Figure 3. Pore size distribution for the two carbon aerogels CA\#1 and CA\#2 (x2) and the layers made with two different Nafion loading 25 and $40 \mathrm{wt} \%$.

The consistency of the pore size values shown on the distributions is confirmed from the TEM observations of carbon aerogels small grains. The sample holder can be rotated so that the same grain can be observed from several angles. Fig. 4 shows several pictures of one CA\#1 grain from different angles $\left(0^{\circ}\right.$ to $\left.90^{\circ}\right)$. Pores from 22 to $66 \mathrm{~nm}$ can be easily seen, which corresponds to the range that is shown on the distributions. 


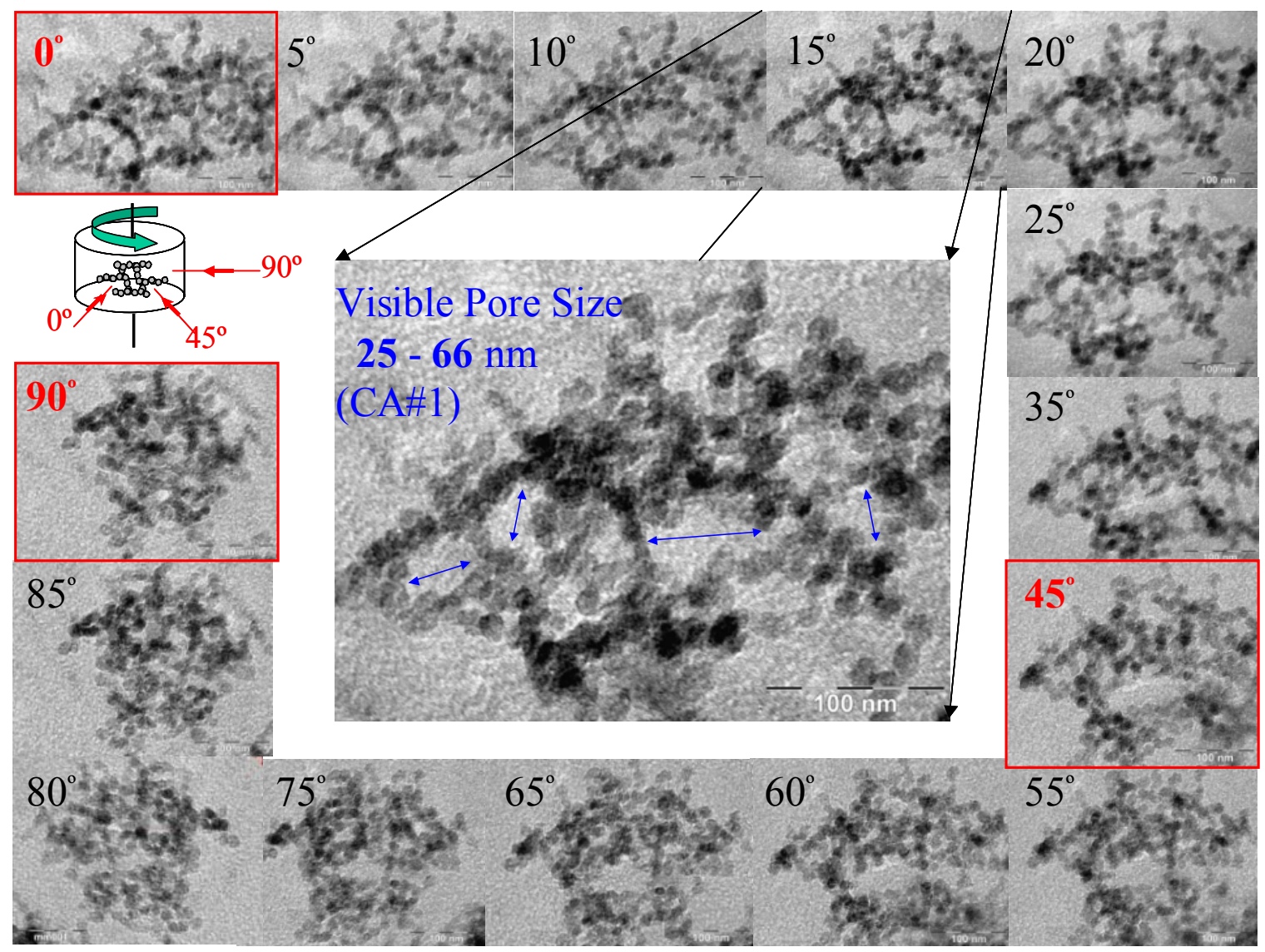

Figure 4. Observation of the pores of a carbon aerogel CA\#1 grain from several angles $\left(0^{\circ}-90^{\circ}\right)$

The porous volume of both carbon aerogels and layers can be graphically compared on Fig. 5. The three grey levels correspond to the three volumes that constitute the porous volume as defined above. The white bars correspond to the full mesoporous volume measured from $\mathrm{N}_{2}$-sorption. It appears clearly that the porous volume variation between the carbon aerogel and the layers is more important for CA\#1 than for CA\#2. This is confirmed by the pore size distribution shown on Fig. 3 where one can see that the Nafion has filled more importantly the porosity of the CA\#1. No pore larger than $20 \mathrm{~nm}$ is measured in CA\#1-based layers whereas some remain in CA\#2 layers. It seems therefore that the larger pores of CA\#1 are more suitable for a good Nafion penetration into the porosity of the carbon aerogel. The increase in Nafion loading from 25 to $40 \mathrm{wt} \%$ did not change a lot the pore size distributions of the layers, only the porous volume are decreased. Finally, all these layers have porous volume that is larger than carbon blackbased catalytic layers porous volume (7). 


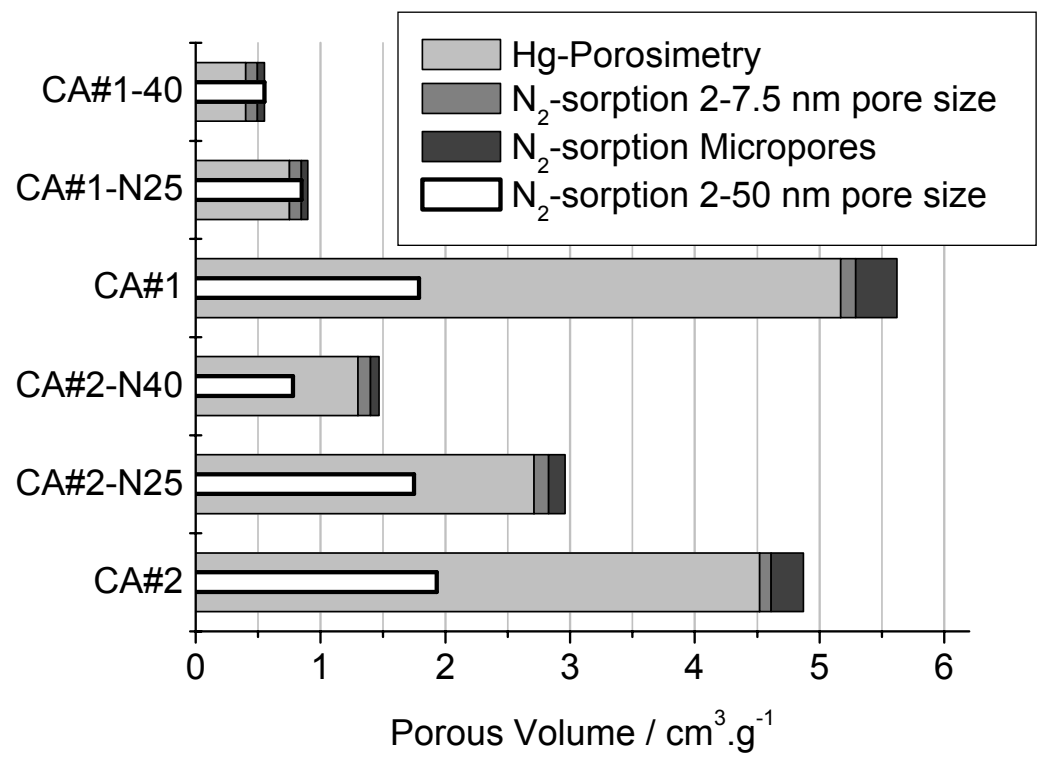

Figure 5. Porous volumes measured from $\mathrm{N}_{2}$-sorption and $\mathrm{Hg}$-porosimetry of the two carbon aerogels $\mathrm{CA \# 1}$ and $\mathrm{CA \# 2}$ and the active layers made using two different Nafion loading 25 and $40 \mathrm{wt} \%$.

\section{$\underline{\text { Catalytic Layers Activity Measurement }}$}

Each electrode was firstly characterized by means of H-adsorption/desorption cyclic voltammetry in order to measure the platinum surface area before the ORR activity measurement. The Pt deposits on our two carbon aerogels were similar following both the same experimental conditions and the fact that the carbon aerogels structures do not to influence the platinum deposit properties measured on rotating disk microelectrode (ORR catalytic activity, surface area) (9). The platinum surface area of the Pt doped CA\#1 and $\mathrm{CA \# 2}$ was $55 \pm 10 \mathrm{~m}^{2} \cdot \mathrm{g}^{-1}$. The ORR activity measurements are shown on Fig. 6 for the various layers. 


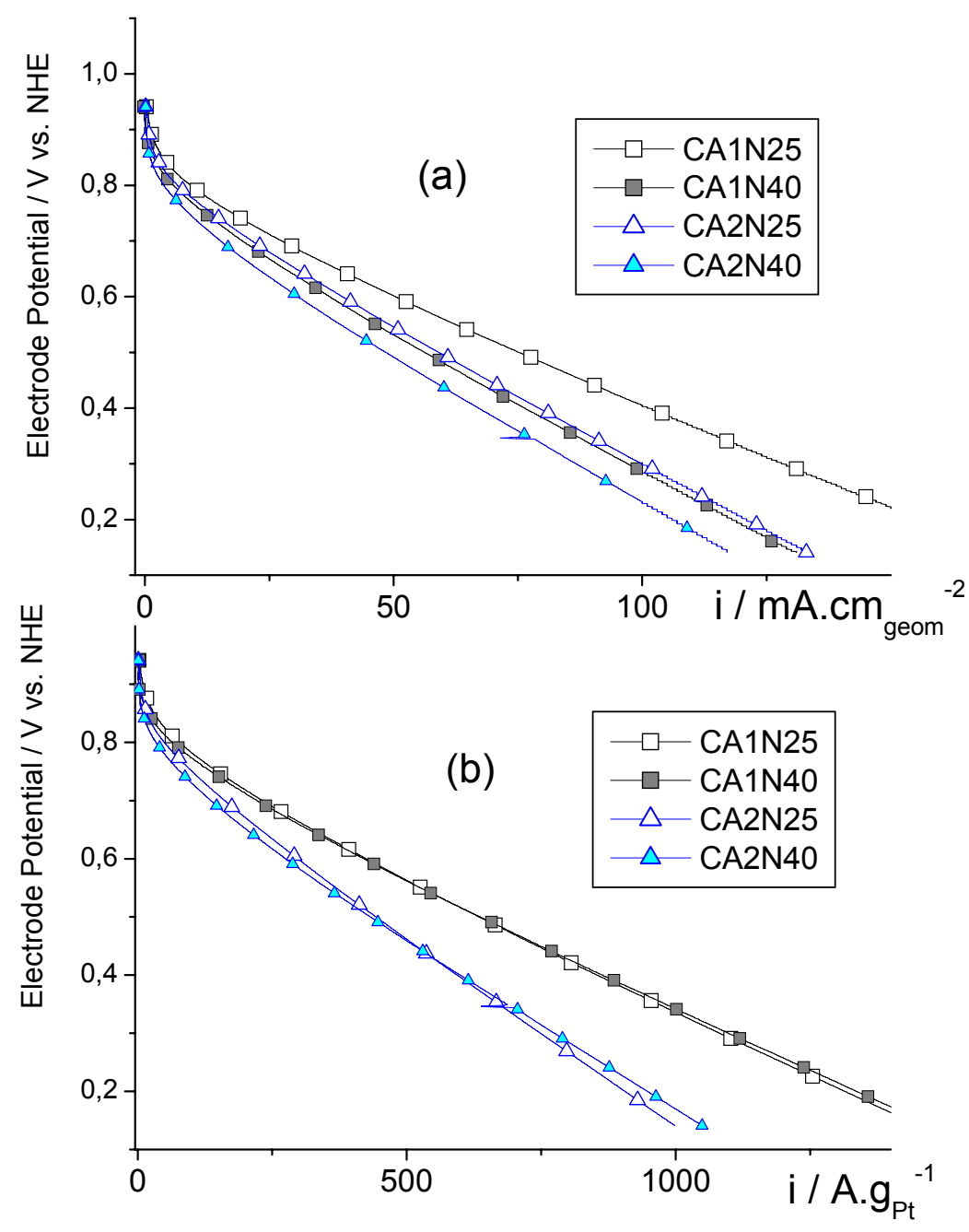

Figure 6. ORR activity measurement (a) Current density, (b) Mass activity at $1 \mathrm{mV} . \mathrm{s}^{-1}$ measured on catalytic layers in half cell conditions; $\mathrm{T}=25^{\circ} \mathrm{C}, \mathrm{P}_{\mathrm{O} 2}=1$ bar, $1 \mathrm{M} \mathrm{H}_{2} \mathrm{SO}_{4}$ electrolyte solution, Pt surface loadings $\left( \pm 0.01 \mathrm{mg} \cdot \mathrm{cm}^{-2}\right): \mathrm{CA} \# 1-\mathrm{N} 25=0.12, \mathrm{CA \# 2- \textrm {N } 2 5}$ $=0.11, \mathrm{CA} \# 1-\mathrm{N} 40=0.09, \mathrm{CA} \# 1-\mathrm{N} 25=0.11 \mathrm{mg} \cdot \mathrm{cm}^{-2}$

The most active layer is the CA\#1-N25 whereas Fig. 5 show that this layer has not the highest porous volume $\left(0.9 \mathrm{~cm}^{3} \cdot \mathrm{g}^{-1}\right)$. The CA\#2 layers have both a higher porous volume than CA\#1-N25 layer ( 3 and $1.4 \mathrm{~cm}^{3} \cdot \mathrm{g}^{-1}$ ). This means that the most important parameter is not the porous volume. Conversely, the initial carbon aerogel pore-size proves to be a key parameter. Indeed, the large pore size of CA\#1, which should enable at the same time a better penetration of the Nafion and a better diffusion of the oxygen, seems to be the most important parameter that can reduce the potential limitation at the PEMFC cathode. Such contribution of the oxygen diffusion limitation has been evidenced from PEMFC experimental results by Gasteiger et al.(10). The conclusion from Uchida et al. (1) when comparing different carbon blacks used in PEMFC cathodes is also similar to our comparison between CA\#1 and CA\#2: the larger pore size carbon yields better fuel cell performance (lower potential limitation). The advantage of the use of carbon aerogels in such a study is that their pore size distribution is more precisely defined thanks to their monolithic structure. Looking further to Fig.6 (a) we can say that the increase of Nafion 
loading brought higher diffusion limitation (measured at high ORR overpotential), which can be linked to the decrease in porous volume, as measured below (Fig. 5). We underline that the activation overpotential (overpotential increase for low current densities) remains quasi-constant for all samples which confirms that the intrinsic electrocatalytic properties for the various layers are rather identical. The reason for the different potential limitations may also be due to different internal resistance of the layers. Nevertheless, we underline that the two layers made with the same Nafion loading (-N25 layers and -N40 layers) have same Pt surface loadings in the measurement error and thus have the same total carbon+Nafion+platinum loading (Fig. 6). Thus, the resistance of these layers may not differ sufficiently to explain their important difference especially between CA\#1-N25 and CA\#2-25 on Fig. 6 (a). Moreover the $100 \mathrm{mV} \cdot \mathrm{s}^{-1}$ cyclic voltammograms showed the same carbon signals for CA\#1-N25 and CA\#2-N25 (Fig. 7). So again we believe that the contribution of the layer resistance to the different response is negligible compared to the contribution of the oxygen diffusion limitation.

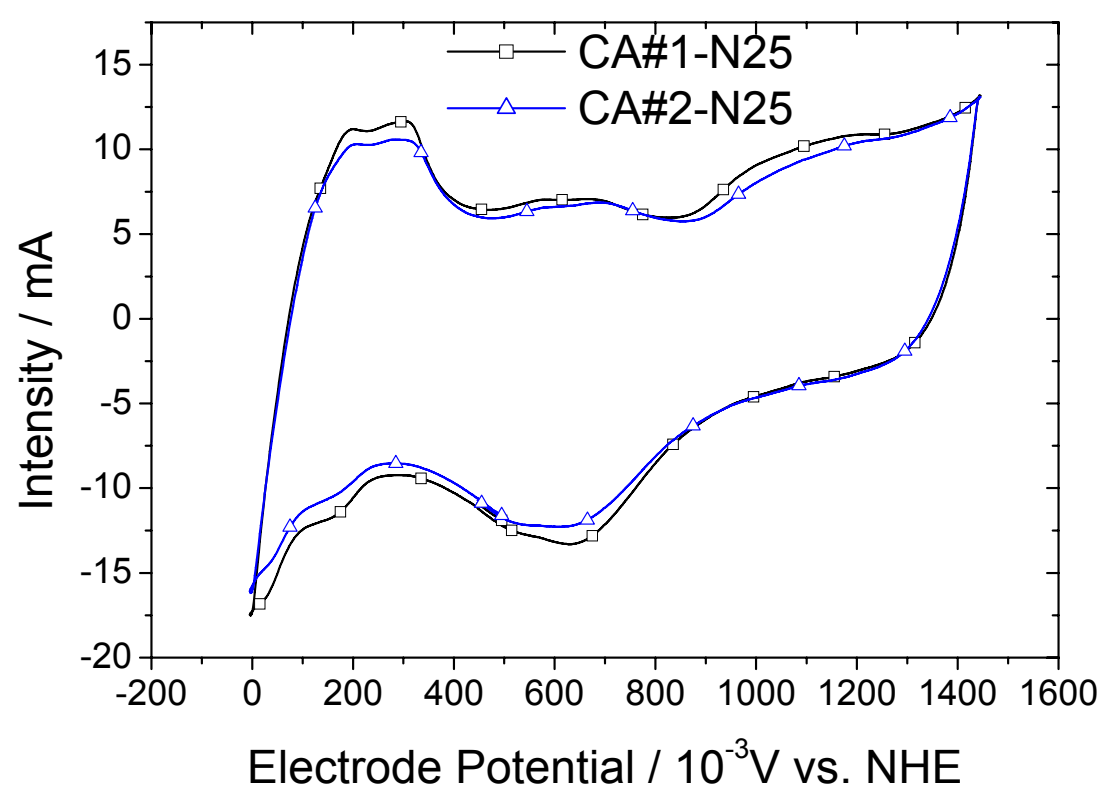

Figure 7. Cyclic voltammograms at $100 \mathrm{mV} \cdot \mathrm{s}^{-1}$ measured on catalytic layers in half cell conditions; $\mathrm{T}=25^{\circ} \mathrm{C}, \mathrm{N}_{2}$ atmosphere, $1 \mathrm{M} \mathrm{H}_{2} \mathrm{SO}_{4}$ electrolyte solution

The interest in using the CA\#1 carbon instead of the CA\#2 carbon is further evidenced on Fig. 6 (b). The graphs indeed show that CA\#1 structure yields higher mass activity than CA\#2, whatever the Nafion loading is. This is an important result highlighting that choosing an appropriate catalyst support (CA\#1 rather than CA\#2) with large pore-size and high surface area will enable to reduce the PEMFC cathode platinum loadings without loosing activity because of the reduction of the oxygen diffusion limitations. 


\section{CONCLUSION}

We synthesized Pt-doped carbon aerogel-based catalytic layers for PEMFC cathodes. Carbon aerogel have high surface area, high porous volume and adjustable pore-size distribution. Thus, they are used for studying the effects of catalytic layer structure on oxygen diffusion potential limitation with constant activation overpotential. The purpose is also to determine which carbon aerogel structure can reduce cathode potential loss and thus yield higher cell performance ( $\mathrm{Pt}$ loading reduction).

In a forthcoming study, we will try to confirm the present results by PEMFC performance measurements that will include in-situ resistance measurements.

\section{Acknowledgments}

Mr Perrin from CEMEF is acknowledged for the TEM analysis.

\section{References}

1. Uchida, M., Aoyama, Y., Eda, N. A. Ohta, J. Electrochem. Soc., 142, 4143 (1995).

2. J. Marie, S. Berthon-Fabry, P. Achard, M. Chatenet, A. Pradourat, E. Chainet, J. Non-Cryst. Solids, 350, 88 (2004).

3. R. W. Pekala, C T Alviso, F. M. Kong and S. S. Hulsey, J. Non-Cryst. Solids, 145, 90 (1992).

4. M. S. Wilson, S. Gottesfeld, J. App. Electrochem., 22, 1 (1992).

5. R. Pirard, C. Alié, J.-P. Pirard, in Handbook of Sol-Gel Science and Technology, Volume II: Characterization of Sol-Gel Materials and Products., S. Sakka, R.M. Almeida, Editors, p211, Kluwer Academic Publishers, London, (2005).

6. O. Antoine, Y. Bultel, R. Durand, J. Electroanal. Chem., 499, 85 (2001).

7. J.C.P. Broekhoff and J.H. de Boer, J. Catal., 9, 8 (1967).

8. J. Xie, K. L. More, T. A. Zawodzinski, J. Electroch. Soc., 151, 1841 (2004).

9. J. Marie, S. Berthon-Fabry, P. Achard, M. Chatenet, E. Chainet, N. Cornet, Oral Communication, $7^{\text {th }}$ European Symposium on Electrochemical Engineering, Toulouse, 5 October 2005.

10. H. A. Gasteiger, S. S. Kocha, B. Sompalli, F. T. Wagner, App. Cat. B, 56, 9 (2005). 